\title{
Effects of Ethanol on Pigeons' Near-Win Responding in a Slot- Machine Analog
}

Alexander A. Ward

Follow this and additional works at: https://researchrepository.wvu.edu/etd

\section{Recommended Citation}

Ward, Alexander A., "Effects of Ethanol on Pigeons' Near-Win Responding in a Slot-Machine Analog" (2014). Graduate Theses, Dissertations, and Problem Reports. 6912.

https://researchrepository.wvu.edu/etd/6912

This Thesis is protected by copyright and/or related rights. It has been brought to you by the The Research Repository @ WVU with permission from the rights-holder(s). You are free to use this Thesis in any way that is permitted by the copyright and related rights legislation that applies to your use. For other uses you must obtain permission from the rights-holder(s) directly, unless additional rights are indicated by a Creative Commons license in the record and/ or on the work itself. This Thesis has been accepted for inclusion in WVU Graduate Theses, Dissertations, and Problem Reports collection by an authorized administrator of The Research Repository @ WVU. For more information, please contact researchrepository@mail.wvu.edu. 


\title{
Effects of Ethanol on Pigeons' Near-Win Responding in a Slot-Machine Analog
}

\author{
Alexander A. Ward \\ Thesis submitted to the Eberly College of Arts and Sciences \\ at West Virginia University \\ in partial fulfillment of the requirements for the degree of \\ Master of Science in \\ Behavior Analysis
}

\begin{abstract}
Elizabeth Kyonka, Ph.D., Chair
Karen G. Anderson, Ph.D.

Steven Kinsey, Ph.D.

Department of Psychology
\end{abstract}

\section{Morgantown, West Virginia}

2014

Keywords: Ethanol, Stimulus Control, Gambling, Key Peck, Peck Rate, Slot Machine, Pigeons

(C) 2014

Alexander Ward

All Rights Reserved 


\begin{abstract}
Effects of Ethanol on Pigeons' Near-Win Responding in a Slot-Machine Analog
\end{abstract}

Alexander Ward

In slot machine play, near wins are losses that are visually similarity to wins and increase gambling persistence, but provide no reinforcer. To measure effects of ethanol on near-win responding, pigeons pecked for food in a slot-machine analog following ethanol administration. In any given trial, one of four outcomes was signaled by consecutive presentations of red or green key lights, followed by a white "collect key." Three red lights signaled a win and three green lights signaled a loss. Two red lights followed by a green light signaled a near win. On winning trials, food was delivered $5 \mathrm{~s}$ after presentation of the white collect key, provided there was at least one peck to the collect key while it was illuminated. The probability of pecking the collect key during losing trial types increased as a function of ethanol dose. Response rates did not change systematically as a function of ethanol dose. Pecks to the collect key were allocated more evenly across all trial types at higher alcohol doses. The time to peck the first presentation of a green key did not decrease systematically as a function of dose. These results provide evidence for a decrease in stimulus discrimination between trial types. 


\section{ACKNOWLEDGEMENTS}

I wish to thank Dr. Elizabeth Kyonka, Dr. Karen G. Anderson, and Dr. Steve Kinsey for serving on my committee and whose support, feedback, and training made this experiment possible. I wish to sincere gratitude to my advisor, Dr. Elizabeth Kyonka, for providing not only the lab in which to run this experiment, but for the encouragement and guidance throughout this project. I would also like to thank my lab mates, Shrinidhi Subramaniam and Nathan Rice for being my official pigeon wranglers during administration days. Finally, I would like to thank my family whose steadfast support not only continues to this day, but has provided me with the learning history that has gotten me this far. 


\section{TABLE OF CONTENTS}

\section{Page}

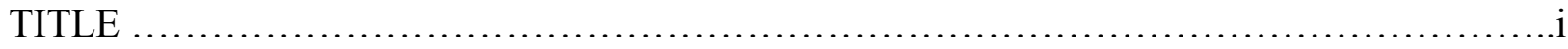

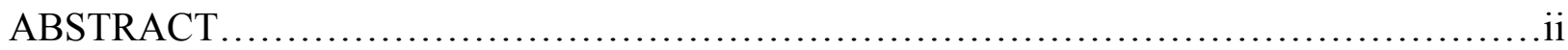

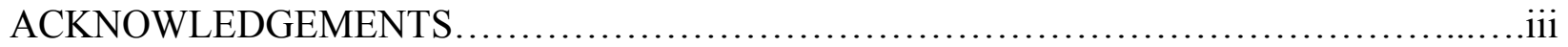

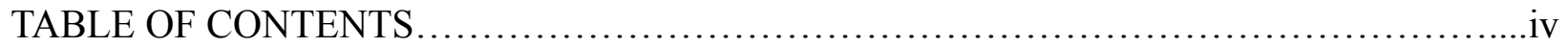

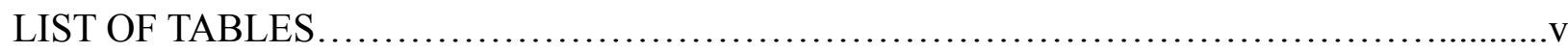

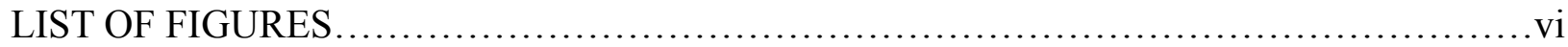

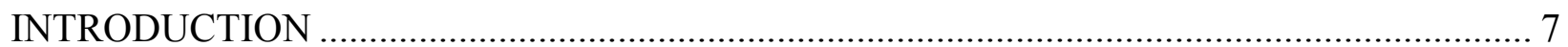

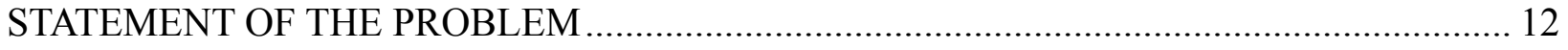

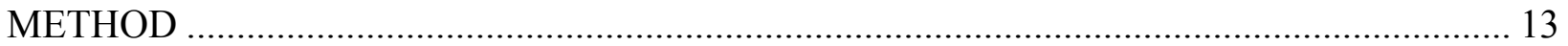

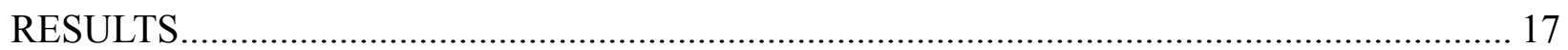

DISCUSSION

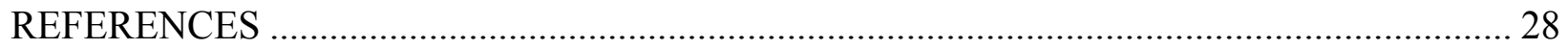

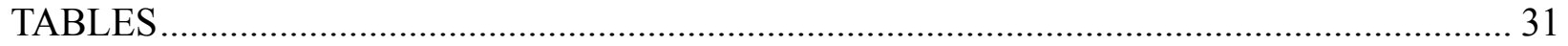

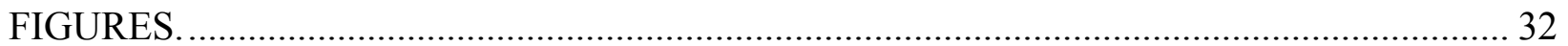




\section{LIST OF TABLES}

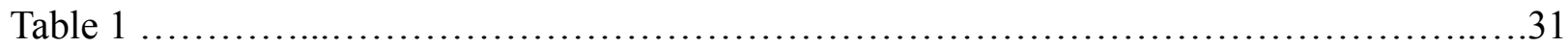

Trials completed at each ethanol administration 


\section{LIST OF FIGURES}

Figure 1

Diagram of slot-machine analog procedure

Figure 2

Mean percentage of trials with collect-phase responses by trial type

Figure 3

Mean percentage of trials with collect-phase responses by dose

Figure 4 35

Near win sensitivity calculated for percentage of trials with collect pecks

Figure 5 36

Mean collect key response rate by trial type

Figure 6

Mean collect key response rate by dose

Figure 7

Near win sensitivity calculated for response rate

Figure 8

Generalization gradient for percentage of pecks across trial types at each dose

Figure 9

Mean delay to peck the first presentation of a green key 


\section{Effects of Ethanol on Pigeons' Near-Win Responding in a Slot-Machine Analog}

Gambling can be defined as engaging in an activity with an uncertain and potentially uncontrollable outcome. Expending energy by foraging for food does not guarantee a satisfying meal, just as betting money at a casino does not guarantee a net gain of funds. In casinos and other establishments that facilitate gambling, a variety of different stimuli often differentially signal wins and losses. For example, three dollar signs on a slot machine signals a jackpot with a large payout while a cherry, dollar sign, and lemon together signal a loss. In some games of chance, some losses are signaled by stimuli that closely resemble winning stimuli. The reels on a slot machine may display all winning symbols save for one reel that displays a symbol indicating a loss. These are "near wins," also called "near misses," so called because of their visual similarity to wins and because gamblers' behavior following near wins can be similar to their behavior following wins, meaning they kept playing (Reid, 1986).

Gamblers place their next bet at a longer latency, or a longer delay, following near wins than following losses (Dixon \& Schreiber, 2004) and near wins lead to more persistent gambling (Côté, Caron, \& Aubert, 2003). The increase in gambling persistence following near wins has been termed the "near-miss effect" (Reid, 1986), or the "near-win effect." The near-win effect is seen in nonhuman animals as well, with rats responding at higher rates on a payout or "collect" key following near wins compared to losses (Peters, Hunt, \& Harper, 2010). In a slot-machine analog procedure, pigeons' near-win response rates on a payout key were higher than response rates for other losses (Kyonka, Rice, \& Ward, 2014 under review). The similarity in behavior following wins and near wins may be increased by the intake of ethanol, prevalent in gambling establishments (Giacopassi, Stitt, \& Vandiver, 1998). The current study aimed to quantify the 
extent to which ethanol dose dependently alters sensitivity to near wins using a slot-machine analog procedure with pigeons.

In gambling situations, near wins increase resistance to extinction and lead to more persistent betting despite repeated losses (Côté et al., 2003). Near wins may increase persistence of gamblers for several reasons including their similarity to wins, subjective dissimilarity to losses (Dixon \& Schreiber, 2004), and their potential function as conditioned reinforcers (Côté et al., 2003). Gamblers' perceptions of, and reactions to, near wins have been measured in several ways, including within-task verbal reports (Delfabbro \& Winefield, 1999), skin conductance (Dixon, Maclaren, Jarick, Fugelsang, \& Harrigan, 2013), and betting latency (i.e., the delay to placing the next bet; Dixon \& Schreiber, 2004).

In spite of the reality that near wins do not signal improved chances of winning, betting is more likely to persist after repeated losses when near wins occur than when near wins do not occur (Côté et al., 2003; Kassinove \& Schare, 2001). Côté and colleagues (2003) speculated that gamblers' betting persistence increased following near wins on a video slot machine because near wins serve as conditioned reinforcers. Because near wins are visually similar to wins, they may be perceived as more similar or closely related to wins than other losses are. Near wins on a standard slot machine were subjectively rated as being "closer to winning" than losses with other combinations of stimuli (Dixon \& Schreiber, 2004). Gamblers' betting latency following near wins was longer than the delay following losses and shorter than following wins. The difference in responding between wins, near wins, and other losses suggests that near wins functionally approximated wins.

Like gambling, alcohol use is widespread, as 52.1\% of Americans over the age of 12 reported being active drinkers of alcohol (RTI International, 2012). Of individuals who met 
criteria for pathological gambling within their lifetime, the prevalence rates of co-morbid drug disorder and alcohol-use disorder were approximately $40 \%$ and $73 \%$, respectively (Petry, Stinson, \& Grant, 2005). In laboratory gambling simulations, intoxicated non-problem gamblers tend to behave like problem gamblers, placing larger bets, losing more quickly, and gambling for longer when faced with repeated losses (Cronce \& Corbin, 2010; Goudriaan, Oosterlaan, de Beurs, \& van den Brink, 2005; Phillips \& Ogeil, 2010). Pathological gamblers and people who are alcohol dependent show decision-making deficits, such as continuing to respond on an option that produced wins frequently but operated at a net loss to the player, compared to individuals who are neither alcohol dependent nor problem gamblers (Goudriaan et al., 2005).

Although researchers have not yet systematically investigated effects of alcohol on sensitivity to near wins in animal or human studies, ethanol has been shown to have dosedependent effects on pigeons' free-operant responding for food reinforcement. In a study by Leander, McMillan and Ellis (1976), a fixed-ratio (FR) 100 and fixed-interval (FI) 5-min multiple schedule arrangement was used to determine effects of ethanol administration on response rates in pigeons. Ethanol increased FI response rates and slightly increased FR response rates at a dose of $1.0 \mathrm{~g} / \mathrm{kg}$ or lower. At the highest dose $(2.0 \mathrm{~g} / \mathrm{kg})$, ethanol suppressed responding, leading to decreased response rates under both conditions. In an FR 30 FI 5-min mixed-schedule arrangement, alcohol was found to decrease pigeons' response rates at all doses above $0.25 \mathrm{~g} / \mathrm{kg}$ (Healey \& Dykstra, 1979). The dose-dependent decrease in responding corroborates findings by Leander and colleagues (1976), but at much lower doses.

More recently, Dayer, Baron, Light and Wenger (2000) administered ethanol to pigeons that were tested in a delayed match-to-sample (MTS) task. At doses that did not lead to an increase in omitted trials $(1.8 \mathrm{~g} / \mathrm{kg}$ to $3.0 \mathrm{~g} / \mathrm{kg})$, MTS accuracy was lower compared to accuracy 
following vehicle. Additional experiments measured accuracy of responding to signal durations in discrete-trial sessions and signal changes during continuous-trial sessions. Across experiments, ethanol decreased overall accuracy of responding by increasing response rates on correct and incorrect answers equally. The highest $(3.0 \mathrm{~g} / \mathrm{kg})$ dose decreased correct responses due to response suppression from the ethanol decreasing overall response rates. At doses below 3.0 $\mathrm{g} / \mathrm{kg}$, ethanol led to decreased MTS accuracy in a way that suggested ethanol decreased pigeons' discrimination of different stimuli. Dayer and colleagues concluded that ethanol impaired pigeons' working memory by decreasing stimulus discriminability.

Ward, Bailey, and Odum (2006) found that alcohol decreased stimulus discrimination in pigeons during a "repeat or vary" task with a 4-response pattern. Frequently emitted response sequences (e.g., repeating a sequence of right, right, left, left) were reinforced with food in the Repeat component, whereas infrequently emitted sequences were reinforced in the Vary component. Following ethanol administration, responding during the Repeat component increased in variability - fewer repeated patterns - while variability of response sequences during the Vary component did not change. The trained target sequence of RRLL occurred more than others in the Vary component following ethanol administration. Sequences that varied by one response, RLLL and RRRL, occurred almost as frequently as the target sequence, suggesting stimulus generalization. The generalization between the target sequence and similar sequences with the increased variability during ethanol sessions suggests difficulty discriminating stimuli following ethanol intake. Impaired stimulus discrimination in this procedure was consistent with the findings in human-subjects research that ethanol intoxication impairs of information processing (Phillips \& Ogeil, 2010). 
Near wins may serve as conditioned reinforcers (Côté et al., 2003), and ethanol may impair discrimination between wins and losses (Dayer, Baron, Light, \& Wenger, 2000) . Because ethanol has been shown to attenuate punishment's suppression of behavior and decrease accuracy in MTS, it can be expected to exacerbate the near-win effect, whether the underlying mechanism is related to stimulus discrimination or conditioned reinforcement.

Peters, Hunt and Harper (2010) measured latency of lever presses and accuracy of responding on the collect lever on winning and losing trials in a slot-machine analog with rats. Pressing a "spin lever" ten times initiated a spin of the slot machine. Upon completion of the 10 responses, between one and five lights were illuminated and a collect lever was inserted into the chamber. If four or five lights were illuminated, pressing the collect lever provided access to sweetened condensed milk as reinforcement. If fewer than four lights were illuminated, lever presses were recorded but had no other programmed consequence. If three lights were illuminated, the outcome was considered a near win. If only one or two lights were illuminated, the outcome was considered a loss. Peters and colleagues measured response latency as the time from trial onset, indicated by presentation of the spin lever, and the first response on that lever. Latencies were longer following wins than losses.

Peters and colleagues (2010) also compared the proportion of trials in which collect-lever presses occurred across trial type. Loss trials were followed by a low proportion of collect-lever responses, whereas wins were followed by a very high proportion of collect-lever responses suggesting stimulus control. Near-win trials were followed by a proportion of collect-lever responses higher than that of losses and lower than wins, demonstrating both stimulus control, and that near wins are very similar to wins. These results were similar to those in human nearwin experiments (e.g., Dixon \& Schreiber, 2004). 
In a slot-machine analog procedure similar to the one used by Peters and colleagues (2010), pigeons pecked red and green key lights, which served as winning and losing stimuli, respectively (Rice \& Kyonka, 2012). Three red lights in a row was a win; a sequence of three green lights was a "clear loss," meaning that a green or losing stimulus was presented before any pecks occurred for that trial. Two red lights followed by a green light was a near win and one red light followed by two green was a loss. For all trial types, the sequence was presented on the same key and a peck to that key advanced the sequence one step. Upon completion of the sequence, the side key was darkened and the center key was illuminated white for $5 \mathrm{~s}$. Pecking this white collect key was followed by food on win trials after the $5 \mathrm{~s}$ had elapsed. For all other trial types, pecking the collect key was recorded but had no other programmed consequences. The rate of pecking the collect key was a function of the number of red stimuli presented, similar to the collect-lever response proportions shown by Peters and colleagues (2010). These findings indicated that the more visually similar a loss is to a win, the more similar a pigeon's behavior will be to its behavior following a win.

\section{Statement of the Problem}

Despite the prevalence of alcohol in gambling environments (Giacopassi, Stitt, \& Nichols, 2006; Giacopassi et al., 1998), effects of alcohol intake on the behavioral processes underlying gambling have not yet been determined experimentally. Similar to results of experiments with human subjects (Dixon \& Schreiber, 2004), the latency between trials was longer following near wins than losses (Peters et al., 2010; Rice \& Kyonka, 2012).

Response latencies on near-win trials were found to be similar to response latencies on small-win trials and different from other losses or large-wins (Peters et al., 2010). Recent results from Kyonka, Rice, and Ward (2014 under review) support and expand upon Peters and 
colleagues' findings, showing that pigeons will stop responding for a short time when first presented with a losing stimulus and will peck to collect reinforcement at a higher frequency with a near-win or win than with a loss or clear-loss outcome.

The purpose of this experiment was to measure sensitivity to near wins following acute ethanol administration in a pigeon slot-machine analog. To assess whether there were dosedependent effects of ethanol on collect-key response rates, ethanol was administered different doses of ethanol $15 \mathrm{~min}$ prior to the beginning of the session. If ethanol decreased trial-type discriminability in this slot machine task, there would be differential changes in response rate across trial types, specifically, increased sensitivity to near wins. This procedure provides the means to differentiate between the underlying mechanisms that lead to observed near-win effects by comparing several dimensions of responding across different trials. An increase in response rates during green-only trials would suggest an impairment of discrimination between trial types, selective changes in response rates on losing trials that included both red and green stimuli would support the idea that near wins operate on gambling behavior through conditioned reinforcement. A decrease in the discriminative power of trial type as a result of ethanol administration may be similar to human gamblers who bet more while intoxicated.

\section{Method}

\section{Subjects}

Five male White Carneau pigeons (Columba livia) pecked lighted keys for food. They were maintained at $85 \%$ of ad libitum weight plus or minus $2.4 \%$ through daily post-session feedings and were housed individually in a vivarium with a 12-hr light:dark cycle with free access to water. All pigeons had experience pecking keys for access to food, but no previous experience with responding in a slot-machine analog. Doses were tested on each pigeon a 
minimum of one full series of doses. Two pigeons (501 and 503) died during the experiment due to unknown causes.

\section{Apparatus}

Four operant-conditioning chambers $(25.5 \mathrm{~cm}$ deep x $32 \mathrm{~cm}$ wide $\times 33.5 \mathrm{~cm}$ high) were each enclosed in a sound-attenuating box containing a ventilation fan to provide air circulation and white noise. Each chamber contained three keys $24 \mathrm{~cm}$ above the floor horizontally arranged $6 \mathrm{~cm}$ apart, a $28-\mathrm{V}$ DC house light located on the back wall at the top of the chamber, and a grain magazine with a $5.5 \mathrm{~cm} \times 6 \mathrm{~cm}$ aperture centered $5.5 \mathrm{~cm}$ above the floor. The house light provided general illumination at all times, except during reinforcer delivery, during all phases of the procedure. The magazine, which was illuminated by a 28-V DC light during reinforcement, contained Nutriblend ${ }^{\mathrm{TM}}$ pigeon feed. Food presentation was controlled through the computer, and consisted of three hopper presentations of $2.5 \mathrm{~s}$ each, separated by $0.5 \mathrm{~s}$ interreinforcement time. A force of approximately $0.15 \mathrm{~N}$ was necessary to operate each key. Experimental events were controlled through a computer and MED-PC ${ }^{\circledR}$ interface located in an adjacent room.

\section{Slot-Machine Analog Procedure}

Each session had a fixed one-hour duration following a 15-min blackout period in order to fit the pharmacokinetic profile of ethanol (Leander et al., 1976). This session design led to a varying number of trials completed in each session. Figure 1A illustrates the sequence of stimuli presented during a trial. Each trial consisted of a response phase followed by a collect phase. At the onset of a trial, either the left or right side key was active and illuminated by a red or green light. The key light and the position of the side key were pseudorandomly selected by the computer. In the response phase, pigeons pecked to advance a sequence of colored key lights. 
Depending on trial type, the key color changed or remained the same. Figure 1B shows all presented combinations of winning and losing stimuli. During a trial, side key lights only changed from red to green. On win trials, three red lights were presented in a row at the beginning of the trial. All other color combinations signaled a losing trial. A presentation of three green stimuli was a clear loss. One red light followed by two green lights was a loss. A combination of two red followed by one green light indicated a near win. All four trial types (win, near win, loss, clear loss) were programmed to occur with equal frequency, and were chosen by the computer from an array of 40 trials, comprised of 10 trials of each type, without replacement.

A collect phase followed completion of all three pecks in the response phase in all trials. In the collect phase, the side key darkened and the center key was illuminated white for $5 \mathrm{~s}$, shown in Figure 1A as the Collect phase. On win trials, food was delivered at the end of the collect phase provided at least one peck to the center key occurred during that time. Immediately following food delivery, the next trial began without an intertrial interval. For all other trial types, pecks to the center key were recorded but had no other programmed consequence; the next trial began after an inter-trial interval equal to the duration of food presentation.

\section{Acute Ethanol Administration}

Ethanol was obtained as a $750 \mathrm{~mL}$ bottle of 190-proof Everclear ${ }^{\circledR}$ from Wine Chateau Inc., in New Jersey. The ethanol was stored in a closed container, at $22^{\circ} \mathrm{C}$. Ethanol administration began after collect-key response rates stabilized in baseline sessions, defined as having no systematic trend for all trial types across five consecutive sessions. Once ethanol administration had begun, ethanol solution or distilled water vehicle was administered via oral gavage once win key response rates returned to within one standard deviation of the established 
baseline rates for all trial types. Ethanol solutions were prepared at different concentrations in distilled water to maintain a constant volume of $5 \mathrm{~mL}$. The largest dose of ethanol administered was $3.0 \mathrm{~g} / \mathrm{kg}$. The vehicle associated with each dose-effect curve was a static $5 \mathrm{~mL}$ of distilled water $(0.0 \mathrm{~g} / \mathrm{kg})$. Concentrations of $0.0,0.3,1.0,1.78$, and $3.0 \mathrm{~g} / \mathrm{kg}$ doses were calculated for each pigeon based on its $85 \%$ ad lib weight.

Doses were administered in ascending order, starting with the $0.0 \mathrm{~g} / \mathrm{kg}$ vehicle $(0.0,0.3$, $1.0,1.78$ or $3.0 \mathrm{~g} / \mathrm{kg}$ ). Two pigeons received a maximum dose of $1.78 \mathrm{~g} / \mathrm{kg}$ while the remaining three received a maximum dose of $3.0 \mathrm{~g} / \mathrm{kg}$. Table 1 shows the number of determinations obtained at each dose for each pigeon. At the end of their first determination, Pigeons 501 and 503 became ill and were removed from the study. Pigeon 504 received three determinations with a maximum dose of $3.0 \mathrm{~g} / \mathrm{kg}$. Following these determinations, Pigeon 504 received two doses of $1.78 \mathrm{~g} / \mathrm{kg}$ and one dose of $3.0 \mathrm{~g} / \mathrm{kg}$ each separated by a vehicle dose. Pigeons 502 and 404 received a maximum dose of $1.78 \mathrm{~g} / \mathrm{kg}$. Subsequent determinations used a maximum dose of $1.78 \mathrm{~g} / \mathrm{kg}$ as the $3.0 \mathrm{~g} / \mathrm{kg}$ dose suppressed responding within sessions.

The next dose of ethanol solution was administered the day after collect-key response rates for each trial type returned to within one standard deviation of the determined baseline rate after disruption by ethanol. A minimum of two and a maximum of 15 sessions were required for responding to return to baseline rates. In seven cases, response rates did not return to the original baseline rate and a new baseline was established using a 10 days of data. This resulted in administration following a minimum of 23 sessions. For a full range of behavioral effects, active doses were expected to be between 0.3 and $3.0 \mathrm{~g} / \mathrm{kg}$, as $0.25 \mathrm{~g} / \mathrm{kg}$ was expected to have no effect, and doses of $3.0 \mathrm{~g} / \mathrm{kg}$ and higher were expected to suppress responding (Healey \& Dykstra, 1979; Ward, Bailey, \& Odum, 2006). 


\section{Results}

\section{Trials Completed}

Table 1 shows the number of trials completed for each administration of ethanol. For estimates of changes in trial completion as a measure of the suppressive effects of ethanol, the number of trials completed in each administration was pooled across pigeons and entered into a one-way analysis of variance (ANOVA) with dose as the factor. There was a significant difference between number of trials completed across doses, $(F(4,36)=11.818, p<.001)$. A post-hoc Games-Howell analysis revealed the largest decrease in trials completed occurred at the highest dose of $3.0 \mathrm{~g} / \mathrm{kg}(M=15.83, S D=12.92)$ which was significantly less than the trials completed at vehicle $(M=138.73, S D=34.424), 0.3 \mathrm{~g} / \mathrm{kg}(M=137.33, S D=37.206)$, and 1.0 $\mathrm{g} / \mathrm{kg}$ doses $(M=115.44, S D=49.36)$. The number of trials completed at the $1.78 \mathrm{~g} / \mathrm{kg}$ dose fell between these values, but was not statistically significantly different from other doses $(M=89$, $S D=47.75$ ). Pigeon 503 completed no trials following the $3.0 \mathrm{~g} / \mathrm{kg}$ dose. Therefore, that session was omitted from the $3.0 \mathrm{~g} / \mathrm{kg}$ data.

\section{Response Proportions}

Figure 2 shows the proportion of trials in which at least one peck occurred during the collect phase for each trial type across all vehicle sessions. The proportion of trials with responses on the collect key increased as a function of the number of red lights presented within the trial. At vehicle administration, pecking occurred on the collect key during all win trials. For overall estimates of differences in responding to winning and losing stimuli, proportions were entered into a repeated-measures ANOVA with trial type as the factor. There was a significant difference between trial types, $(F(3,12)=193.49, p<.001)$. A linear-trend analysis confirmed 
that the probability of responding during on the collect phase increased linearly as a function of the number of red lights presented in a given trial $\left(F_{\text {linear }}(1,4)=2576.35, p<.001\right)$.

To determine effects of ethanol dose on trial-type discrimination in the slot-machine analog, the proportion of trials in which a pecks to the collect key occurred at least once was calculated for each trial type in each vehicle or ethanol administration session. All pigeons completed at least one series of ethanol doses. Pigeons 501, 503, and 504 received a maximum dose of $3.0 \mathrm{~g} / \mathrm{kg}$. For Pigeon 503, $3.0 \mathrm{~g} / \mathrm{kg}$ ethanol completely suppressed pecking during behavioral testing on the day of dosing and for three days following. No key peck data were recorded for Pigeon 503 at $3.0 \mathrm{~g} / \mathrm{kg}$. Pigeons 502 and 404 received a maximum dose of 1.78 $\mathrm{g} / \mathrm{kg}$. Figure 3 shows the proportion of trials with collect-phase responding plotted as a function of dose. Collect-phase responding occurred on all win trials with exceptions for Pigeon 502 at $0.3 \mathrm{~g} / \mathrm{kg}$ and $1.78 \mathrm{~g} / \mathrm{kg}$ doses, and Pigeon 404 at $1.0 \mathrm{~g} / \mathrm{kg}$ doses. Overall, the proportion of loss, clear-loss, and near-win trials with collect-phase responding increased as a function of dose except for near-win proportions for Pigeons 502 and 404. Data were pooled across pigeons and separate linear regressions were calculated for the for each trial type to assess whether there were systematic, dose-dependent changes in the proportions of trials with at least collect-phase peck. Across doses, there was no significant change $\left(R^{2}=.003, b=-.052, F(1,18)=.05, p=.83\right)$ in the proportion of trials in which pigeons pecked the collect key following winning stimuli for any pigeon. As ethanol dose increased, pecks to the collect key occurred more often following clear losses $\left(R^{2}=.82, b=.90, F(1,18)=79.83, p<.001\right)$, losses $\left(R^{2}=.76, b=.87, F(1,18)=\right.$ $56.58, p<.001)$, and near wins $\left(R^{2}=.44, b=.67, F(1,18)=14.38, p=.001\right)$.

For a quantitative assessment of sensitivity to near wins, the collect key response probability from near-win trials was divided by the collect-key response probability from win 
trials. A ratio of 1 would mean that pecks were equally likely on the collect-key during near-win and win trials. If the ratio approached zero, collect response probability from near wins was dissimilar from collect response probability from wins, indicating decreased sensitivity to near wins. Figure 4 shows sensitivity to near wins plotted as a function of ethanol dose, and averaged within ethanol administration sessions. A linear regression was calculated to assess whether a dose-dependent change occurred in sensitivity to near wins. Regression revealed a systematic increase in sensitivity to near wins for pooled data $\left(R^{2}=.441, b=.664, F(1,18)=14.22, p<\right.$ $.001)$. The sensitivity to near wins calculated for collect-phase response probability increased dose dependently, meaning that the likelihood of collect-phase responding during near-win trials increased in relation to the probability during wins.

There was a selective, dose-dependent effect on the percentage of collect phases with responses across all loss trial types: collect phase responding increased as a function of ethanol dose. By contrast, no changes in collect-phase responding were observed following wins. Sensitivity to near wins increased as a function of ethanol dose. Pecking occurred on the collect key on winning trials, regardless of ethanol dose. Taken together, these results indicate that ethanol administration caused all losing trial types to be treated more similarly to wins.

\section{Response Rates}

Figure 5 shows response rates on the collect key across trial type, calculated for all trials with at least one peck to the collect key. Trials without collect-phase responding were excluded. Response rates increased as a function of trial type. A repeated-measures ANOVA on response rate with trial type as a factor was conducted to determine whether there was a change in response rate as a function of trial type. Following vehicle administration, there was a significant main effect of trial type on response rate, $(F(3,12)=10.47, p=.001)$, and a trend analysis 
revealed that response rate during the collect phase was a linear function of trial type, $\left(F_{\text {linear }}(1\right.$, $4)=15.07 ., p=.018$ ). Lower response rates to the collect key were observed following clear losses $(M=0.04, S D=0.03)$ and losses $(M=0.35, S D=0.35)$, whereas the highest response rates followed wins $(M=2.81, S D=0.81)$. Response rates on near-win trials $(M=1.02, S D=$ 0.67) were lower than rates of wins but higher than other losses. Response rates of zero were within one standard deviation of the mean for both clear-loss and loss trial types, which is not true for near-win and win trials.

By calculating response rate, dose-dependent differences for all trial types could be compared. Following vehicle administration, response rates across pigeons were a function of trial type, increasing with the number of red lights in a given trial. Figure 6 shows response rates calculated as the number of pecks per session, during trials with at least one peck to the collect key, plotted as a function of ethanol dose. Response rate increased for clear losses as a function of dose, but not for any other trial type. The bottom right panel in Figure 6 shows a systematic dose-dependent increase in response rates during clear-loss as a function of dose $\left(\mathrm{R}^{2}=.21, b=\right.$ $.46, F(1,18)=4.79, p=.042)$. There was no significant increase in response rates for loss $\left(\mathrm{R}^{2}=\right.$ $.02, b=-.15, F(1,18)=.39, p>.05)$, near-win $\left(\mathrm{R}^{2}=.006, b=-.08, F(1,18)=.114, p>.05\right)$ or win $\left(\mathrm{R}^{2}=.04, b=-.20, F(1,18)=.041, p>.05\right)$ trials.

Figure 7 shows the near-win sensitivity ratio (near wins divided by wins), calculated using response rates and plotted as a function of ethanol dose, averaged within ethanol administration sessions. Sensitivity to near wins was averaged across pigeons within each set of doses. A linear regression assessed whether a dose-dependent change occurred in sensitivity to near wins as a function of ethanol dose. Regression revealed no systematic increase in sensitivity 
to near wins overall $\left(R^{2}=.073, b=.27, F(1,19)=1.42, p>.05\right)$, suggesting that the sensitivity to near wins calculated for peck rate did not change dose dependently.

\section{Generalization Curve}

Figure 8 shows generalization gradients, calculated as the percentage of collect-phase responses for each trial type at each administration. A higher value on one trial type indicated an increased allocation of pecks compared to other trial types. Following vehicle administration, $68.81 \%$ of pecks occurred following wins, more than any of the other outcomes. The generalization gradients appear similar to the absolute rates of responding in Figure 6. The lack of one-to-one correspondence means that absolute and relative response rates were both changing. A flattening of the curve, shown for Pigeons 501 and 502 at $3.0 \mathrm{~g} / \mathrm{kg}$, means that pecks were allocated evenly across trial types. A steep slope in Figure 8, shown at vehicle for pigeons $501,503,404$, and 504 indicated greater discrimination between trial outcomes, meaning that more collect phase pecks were allocated to win trials than other trial types. Across all pigeons, there was a systematic dose-dependent flattening of the discrimination curve as ethanol dose increased, meaning that pecks were allocated more evenly across trial types.

\section{Delay to Peck on First Green Key}

One potential explanation for dose-dependent effects of ethanol on near-win sensitivity is that ethanol has an anxiolytic effect. Delay to peck the first presentation of a green, or losing, stimulus suggests that losing stimuli are aversive. If ethanol had an anxiolytic effect, a dosedependent decrease in time to peck the first green key during a response phase would occur. Figure 9 shows the delay to peck the first green key, the first signal that the trial cannot end with food delivery. This response-phase latency was plotted as a function of trial type. In order to test whether ethanol attenuated the putative aversive effects of losing stimuli, latency to peck the first 
green key during the response phase of losing trials was calculated for each trial type. Pigeon 502 had multiple instances of extreme delays to start clear-loss trials, longer than $30 \mathrm{~s}$, to peck the first green key presentation during clear losses. Therefore, outlying delays were identified and eliminated using a boxplot analysis. Delays that were more than 1.5 interquartile ranges above the $75^{\text {th }}$ quartile were omitted. In total, 16 outliers were identified and omitted: two delays were longer than $38 \mathrm{~s}$, and 16 were longer than $118 \mathrm{~s}$.

However, Figure 9 shows no dose-dependent decrease in time to peck the first presentation of a green key during the response phase for losing trials. Separate linear regressions were calculated using pooled data for each trial type. Across doses, there was no significant change in the latency to peck the first green in clear-loss $\left(R^{2}=.14, b=.38, F(1,18)=\right.$ $2.999, p>.05)$, loss $\left(R^{2}=.03, b=-.16, F(1,18)=.47, p>.05\right)$, or near-win $\left(R^{2}=.003, b=-.23\right.$, $F(1,18)=1.03, p>.05)$ trials for any pigeon. The time to peck the first green key during response phases did not change significantly as a function of dose.

\section{Discussion}

It has been suggested that alcohol leads to continued and more rapid losses when gambling when compared to outcomes of sober gamblers. In this study, effects of ethanol on pigeons' responding in a slot-machine analog were assessed. Across all pigeons, the probability of pecking the collect key during near-win trials increased dose dependently, including trials that occurred following the $3.0 \mathrm{~g} / \mathrm{kg}$ dose, despite a decrease in the number of trials completed overall. One potential shortcoming of this study is that there were relatively few administrations of the $3.0 \mathrm{~g} / \mathrm{kg}$ dose. Pigeons 501 and 503 had the only usable data of the three pigeons that received the $3.0 \mathrm{~g} / \mathrm{kg}$ dose, with Pigeon 504 receiving the most administrations. The $1.78 \mathrm{~g} / \mathrm{kg}$ dose did not engender a large or consistent decrease in the number of trials completed, making it 
difficult to determine the accuracy of other measures due to suppressive effects of doses higher than the $1.78 \mathrm{~g} / \mathrm{kg}$ dose. Whether ethanol caused a devaluation of reinforcement or suppressed responding is beyond the scope of this study and the measures used.

There were no systematic changes in peck rates across doses. Even at the highest dose, win rates remained stable, and remained a function of the number of red lights during the response phase. In order to support the explanation that stimulus discrimination decreased, the rate of collect key pecking during win trials would be expected to decrease. For some pigeons, there was a decrease in rate of pecking the collect key during win trials, whereas some pigeons had an increased rate of pecking the collect key across loss trials. These findings were inconsistent with those of past studies measuring effects of ethanol on responding (Healey \& Dykstra, 1979; Leander et al., 1976). In both studies, there was a decrease in response rate at doses above $0.25 \mathrm{~g} / \mathrm{kg}$. Response rate did not decrease in the current study. One reason for these findings may be that in the extant literature, effects of ethanol were measured using schedulecontrolled response rates. The collect key in the current experiment was not programmed as an interval or ratio schedule. The lack of systematic difference in collect key response rates is unconvincing, given the data for individual pigeons.

The increase in probability to peck the collect key during near wins at higher doses supports the hypothesis that ethanol leads to decreased discrimination between near-win and winning trials. The proportion of trials with responding at vehicle in the current study increased as a function of trial type. This is similar to findings by Peters and colleagues (2010) in which the proportion of trials with collect-lever presses was measured. The dose-dependent increase in response probability during loss trials without systematic changes in response rates suggests that discrimination between trial types was impaired. This is similar to findings in human gambling 
literature (Dixon \& Schreiber, 2004) that showed an increase of average bet amount following alcohol administration. However, the conflicted measures of arousal coupled with the small effect size mean that deciding on one explanation for these effects is difficult.

Analysis of the distribution of pecks across trial types allowed for a comparison between absolute and relative response rates on the collect key and provided a measure of generalization between trial types. Pecks were distributed more evenly across trials at higher doses of ethanol, indicating generalization between trial types. A dose-dependent flattening of the discrimination curve occurred: the absolute number of pecks per opportunity to the collect key was similar across trial types at higher doses of ethanol. A substantive body of empirical research documenting human gambling behaviors following ethanol intake (Dixon et al., 2013; Phillips \& Ogeil, 2010) is broadly consistent with the notion that alcohol impairs ability to discriminate. Dixon and colleagues measured skin conductance as a measure of frustration when bets resulted in near wins. Skin conductance and key pecking are both measures of arousal. Therefore, an increase in likelihood of pecking would be similar to a human's physiological or verbal response following outcome presentation in gambling tasks.

A number of potential alternative explanations for the results in the present study exist. For example, ethanol has been shown to ameliorate punishing effects of stimuli provided response rates were not reduced to near-zero levels (Leander, 1975; Vogel-Sprott, 1967). If what occurred was a devaluation of punishers, clear-loss and loss outcomes (zero and one red lights, respectively) would not be expected to have increased response rates or response likelihood. While response rates did not increase systematically as a function of ethanol dose, response probability increased across all losing trial types. The increase in probability of pecking the collect key across losing trial types provides evidence for the possibility that ethanol decreased 
loss aversiveness. However, the delay to peck the first presentation of a green key did not decrease as a function of ethanol dose. In fact, in instances when dose would be expected to have a significant effect on delay to peck, regression revealed no systematic change. The findings of the current study are inconsistent with past findings that demonstrated that low doses of ethanol attenuated suppressive effects of aversive shocks (Vogel-Sprott, 1967). Vogel-Sprott examined shock presented in tandem with reinforcement; therefore, the effect of losing stimuli on the collect key may be explained by a different mechanism than what was captured in this study. The lack of systematic effects at the highest doses of ethanol provide support for the explanation that ethanol decreases stimulus discrimination when gambling, without making the collect key the primary controlling stimulus.

The inclusion of probability data is not sufficient for this explanation. It would be possible to say that by looking only at the likelihood of collect-phase pecking alone, the white key became the primary stimulus controlling behavior. Peck-probability data are unable to capture this difference. Response-rate data are needed in conjunction with the probability of pecking in order to make accurate statements regarding the nature of these findings. Response rate varied as a function of the number of red lights presented during the response phase in each trial across doses. These systematic differences were consistent with previous findings using the slot-machine analog (Kyonka et al., 2014 under review; Rice \& Kyonka, 2012), indicating that winning stimuli engender higher response rates, even when presented in an overall losing arrangement.

Alternatively, ethanol may have increased the conditioned reinforcing effects of winning stimuli. If this was the case, increased probability of pecking during the collect phase would not be expected in clear-loss trials when no winning stimuli are presented. Additionally, the 
proportion of responses across trial types would be expected to follow a different curve than the curve at vehicle. A larger proportion of pecks would occur for near wins and losses than clear losses. Instead, a flattening of the curve occurred, indicating that the number of pecks during the collect phase became more similar across trial types.

The collect-key peck-probability data in the current study provides further evidence for dose-dependent changes in stimulus discrimination in a gambling task. Were trials being correctly discriminated and the subjective reinforcing values of each trial type were altered, the probability of pecking during the collect phase in a loss trial would not increase. Of note is that while there was an increased probability of pecking across all loss types as a function of dose, there was no decrease in the probability of pecking following wins. This means that while losing trials were being treated as winning trials, winning trials were not necessarily being treated as losing trials. Therefore, the best explanation for the dose-dependent effects of ethanol in the current study is one of stimulus generalization between trial types.

The inclusion of alcohol into an existing slot-machine analog provided new insight into effects of ethanol on sensitivity to near wins in a slot-machine analog. While not the overall purpose of this study, a potential limitation of this study is that the pigeons did not gamble or risk any access to food in order to complete trials. Wins, and therefore access to reinforcement, occurred in $25 \%$ of trials. However, the majority of extant literature on human gambling also used contrived tasks that did not involve gambling risks for ethical or procedural reasons (Weatherly \& Derenne, 2007). Near wins are ubiquitous to slot machines, and serve to extend gambling persistence. In the present study, effects of ethanol on sensitivity to near wins suggest that ethanol led to decreased discrimination between wins and losses. 
The findings in this study have yet to be extended to human subjects. Future studies using ethanol can help in the interpretation of these findings in relation to effects of ethanol on nearwin sensitivity in humans. A longer session duration may help identify the time at which responding is maximally affected by ethanol. Further, resistance to extinction has not yet been examined using this procedure. Future studies would need to balance between a behaviorally active ethanol dose, and a dose that has suppressive effects.

The effect of ethanol on sensitivity to near wins is an interesting phenomenon. This study yielded mixed results that require further investigation, but combined a pharmacological intervention with an animal slot-machine analog that produced behavior similar to that found in human gambling. Overall, there is evidence that suggests discrimination between losses and winning outcomes was disrupted by ethanol. 


\section{References}

Côté, D., Caron, A., \& Aubert, J. (2003). Near wins prolong gambling on a video lottery terminal. Journal of Gambling Studies, 19(4), 433-438. doi:10.1023/A:1026384011003

Cronce, J. M., \& Corbin, W. R. (2010). Effects of alcohol and initial gambling outcomes on within-session gambling behavior. Experimental and Clinical Psychopharmacology, 18(2), 145-57. doi:10.1037/a0019114

Dayer, C. a, Baron, S., Light, K. E., \& Wenger, G. R. (2000). Effects of ethanol on working memory and attention in pigeons. The Journal of Pharmacology and Experimental Therapeutics, 293(2), 551-8.

Delfabbro, P., \& Winefield, A. (1999). Poker-machine gambling: An analysis of within session characteristics. British Journal of Psychology, 1997, 76-86.

Dixon, M. J., MacLaren, V., Jarick, M., Fugelsang, J. A., \& Harrigan, K. A. (2013). The frustrating effects of just missing the jackpot: slot machine near-misses trigger large skin conductance responses, but no post-reinforcement pauses. Journal of Gambling Studies / Co-Sponsored by the National Council on Problem Gambling and Institute for the Study of Gambling and Commercial Gaming, 29(4), 661-74. doi:10.1007/s10899-012-9333-x

Dixon, M. R., \& Schreiber, J. (2004). Near-miss effects on response latencies and win estimations of slot machine players. The Psychological Record, 54(3), 335-348.

Giacopassi, D., Stitt, B. G., \& Nichols, M. (2006). Motives and methods of under-age casino gamblers. Journal of Gambling Studies / Co-Sponsored by the National Council on Problem Gambling and Institute for the Study of Gambling and Commercial Gaming, 22(4), 413-26. doi:10.1007/s10899-006-9026-4 
Giacopassi, D., Stitt, B. G., \& Vandiver, M. (1998). An Analysis of the Relationship of Alcohol to Casino Gambling Among College Students. Journal of Gambling Studies / Co-Sponsored by the National Council on Problem Gambling and Institute for the Study of Gambling and Commercial Gaming, 14(2), 135-149.

Goudriaan, A. E., Oosterlaan, J., de Beurs, E., \& van den Brink, W. (2005). Decision making in pathological gambling: a comparison between pathological gamblers, alcohol dependents, persons with Tourette syndrome, and normal controls. Brain Research. Cognitive Brain Research, 23(1), 137-51. doi:10.1016/j.cogbrainres.2005.01.017

Healey, M. L., \& Dykstra, L. A. (1979). Joint effects of ethanol and caffeine on schedulecontrolled responding in the pigeon. Psychopharmacology, 62(2), 141-4.

Kassinove, J. I., \& Schare, M. L. (2001). Effects of the "near miss" and the "big win" on persistence at slot machine gambling. Psychology of Addictive Behaviors, 15(2), 155-158. doi:10.1037//0893-164X.15.2.155

Kyonka, E. G. E., Rice, N., \& Ward, A. A. (2014). Stimulus Discrimination in a Pigeon Slot Machine Analog. Journal of Experimental Psychology: Animal Learning and Cognition (Under Review).

Leander, J. (1975). Rate-dependent Effects of drugs. II. effects of some major tranquilizers on multiple fixed-ratio, fixed-interval schedule performance. The Journal of Pharmacology and Experimental Therapeutics, 193(2), 689-700.

Leander, J., McMillan, D. E., \& Ellis, F. W. (1976). Ethanol and isopropanol effects on schedulecontrolled responding. Psychopharmacology, 47(2), 157-164. doi:10.1007/BF00735815 
Peters, H., Hunt, M., \& Harper, D. (2010). An animal model of slot machine gambling: the effect of structural characteristics on response latency and persistence. Journal of Gambling Studies, 26(4), 521-31. doi:10.1007/s10899-010-9183-3

Petry, N. M., Stinson, F. S., \& Grant, B. F. (2005). Comorbidity of DSM-IV pathological gambling and other psychiatric disorders: results from the National Epidemiologic Survey on Alcohol and Related Conditions. The Journal of Clinical Psychiatry, 66(5), 564-74.

Phillips, J. G., \& Ogeil, R. P. (2010). Alcohol influences the use of decisional support. Psychopharmacology, 208(4), 603-11. doi:10.1007/s00213-009-1762-6

Reid, R. L. (1986). The psychology of the near miss. Journal of Gambling Behavior, 2(1), $32-$ 39. doi:10.1007/BF01019932

Rice, N., \& Kyonka, E. G. E. (2012). The Conditioned Value of Stimuli that Signal Wins Control Response Rate in a Pigeon Slot Machine Analogue with Near Wins. In Poster Presented at the Society for the Quantitative Analysis of Behavior.

RTI International. (2012). Results from the 2012 National Survey on Drug Use and Health : Summary of National Findings.

Vogel-Sprott, M. (1967). Alcohol effects on human behaviour under reward and punishment. Psychopharmacology, 344, 337-344.

Ward, R. D., Bailey, E. M., \& Odum, A. L. (2006). Effects of D-Amphetamine and Ethanol on Variable and Repetitive Key-Peck Sequences in Pigeons. Journal of the Experimental Analysis of Behavior, 86(3), 285-305. doi:10.1901/jeab.2006.17-06

Weatherly, J. N., \& Derenne, A. (2007). Rats playing a slot machine: a preliminary attempt at an animal gambling model. Analysis of Gambling Behavior, 1(2), 79. 
Table 1

The number of ethanol administrations and the total number of trials completed for each dose of EtOH in order of administration.

Dose $(\mathrm{g} / \mathrm{Kg}) \quad$ Trials Completed

Pigeon 501

$0.00 \quad 163$

$0.30 \quad 162$

$1.00 \quad 160$

$3.00 \quad 12$

$\begin{array}{lc} & \text { Pigeon } 502 \\ 0.00 & 161,86 \\ 0.30 & 93,83 \\ 1.00 & 72,58 \\ 1.78 & 67,21 \\ & \text { Pigeon } 503 \\ 0.00 & 172 \\ 0.30 & 164 \\ 1.00 & 160 \\ 3.00 & 0 \\ & \text { Pigeon } 404 \\ 0.00 & 162,106 \\ 0.30 & 159,89 \\ 1.00 & 184,102 \\ 1.78 & 166,101 \\ & \text { Pigeon } 504 \\ 0.00 & 168,134,167,127,80 \\ 0.30 & 153,173,160 \\ 1.00 & 48,145,10 \\ 1.78 & 100,79 \\ 3.00 & 13,37,9,24 \\ & \end{array}$

Note. The number of ethanol administrations and the total number of trials completed for each dose of EtOH in order of administration. Successive administrations of a given dose are presented on the same line, separated by commas. 


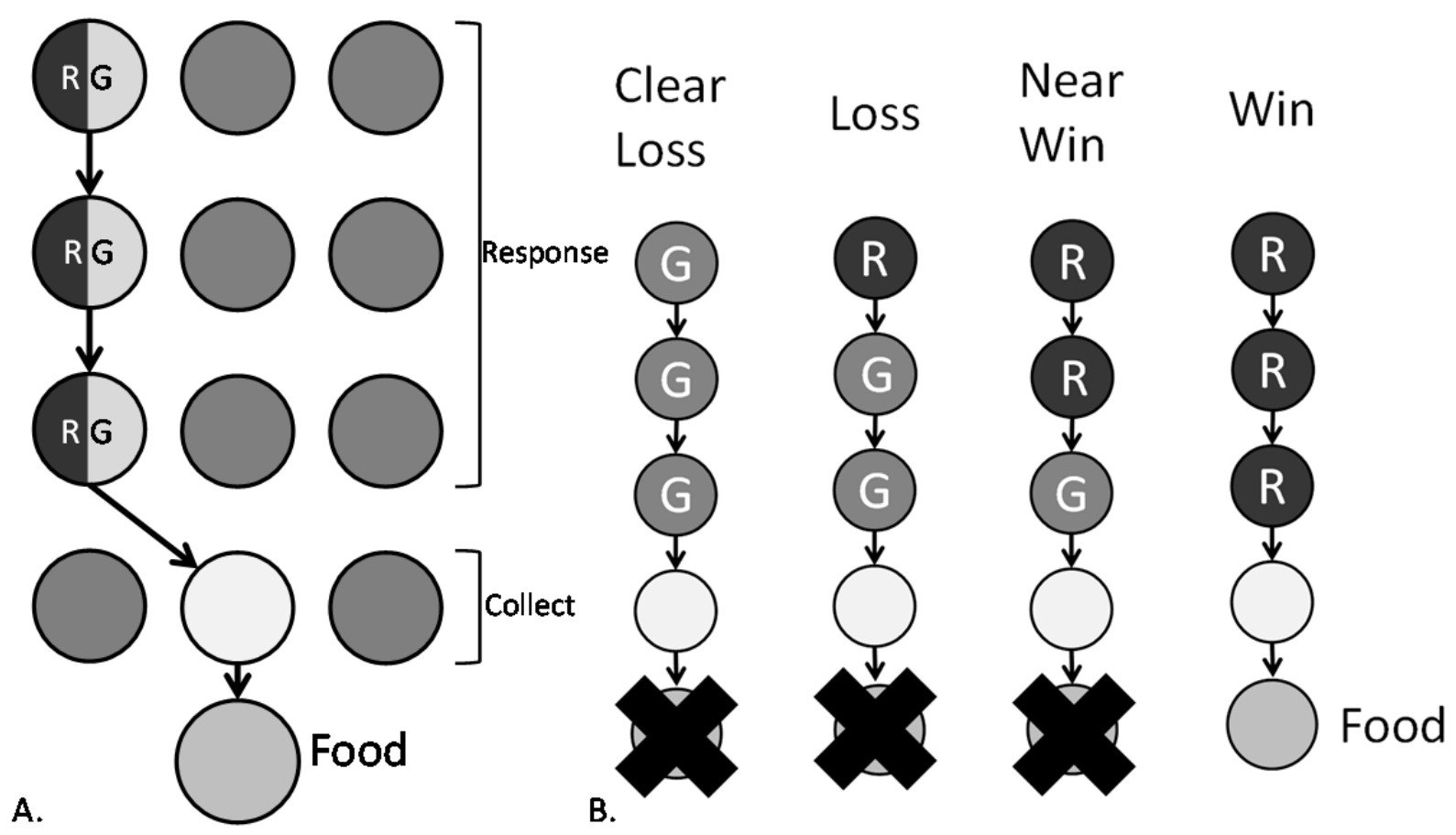

Figure 1. (A) Trial progression: At trial onset, one side key was illuminated either red (R) or green $(\mathrm{G})$. With each peck, the trial advanced to the next step. The key remained green, remained red, or switched from red to green depending on trial type. After 3 pecks, the side key was darkened, and the center key was lighted white for $5 \mathrm{~s}$. Responding on this key at least once during the 5-s illumination gave access to food at the end of the cycle on win trials. No food was delivered following loss trials. (B) There were four trial types: Clear loss, loss, near win, and win. Three-step stimulus arrangements and trial outcomes are shown. Clear loss trial types had no reds, losses had one red, near wins had two reds, and wins had three red lights displayed during the response phase. 


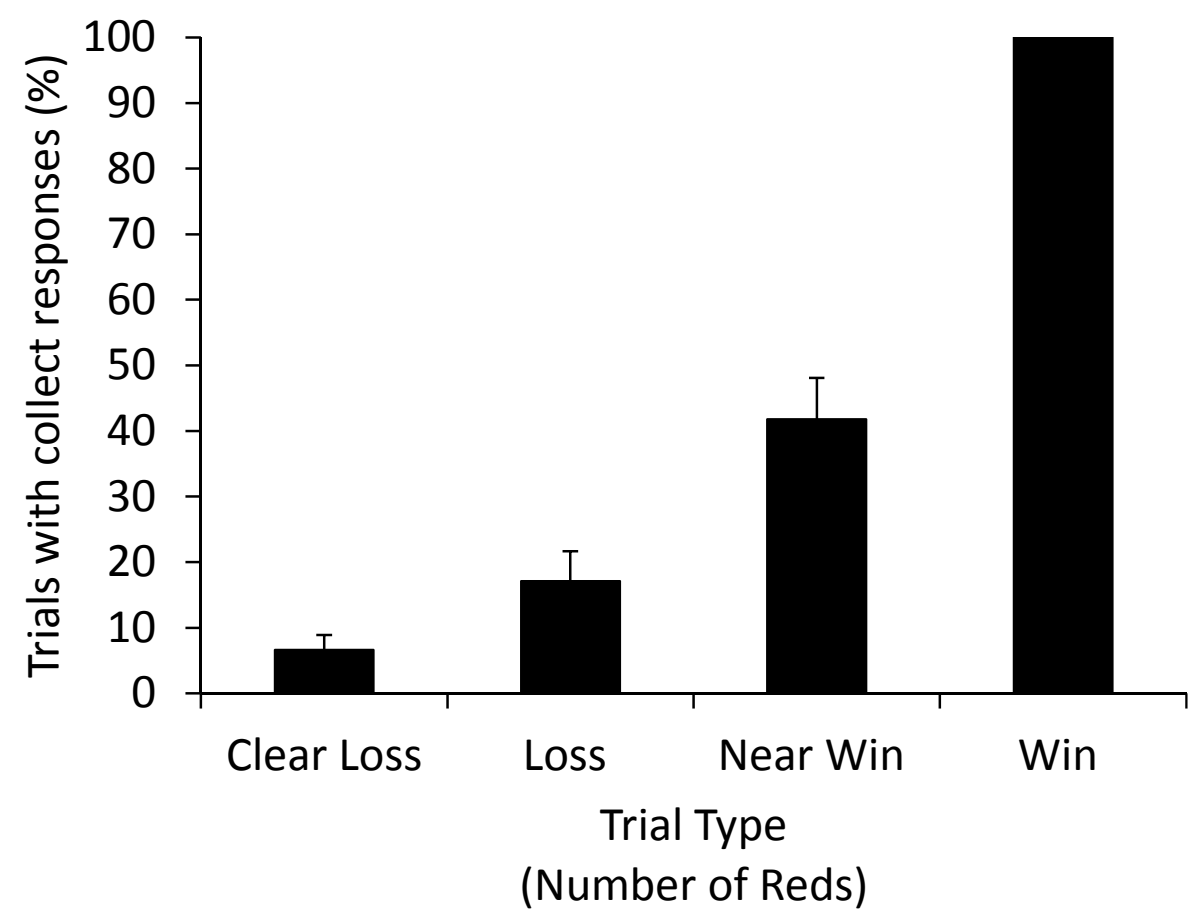

Figure 2. Mean percentage of trials with collect-phase responses plotted as a function of trial type, or the number of red lights in the response phase, at vehicle. The percentage of trials with responses on the collect key increased as a function of the number of red lights presented within the trial. Bars indicate standard error. 


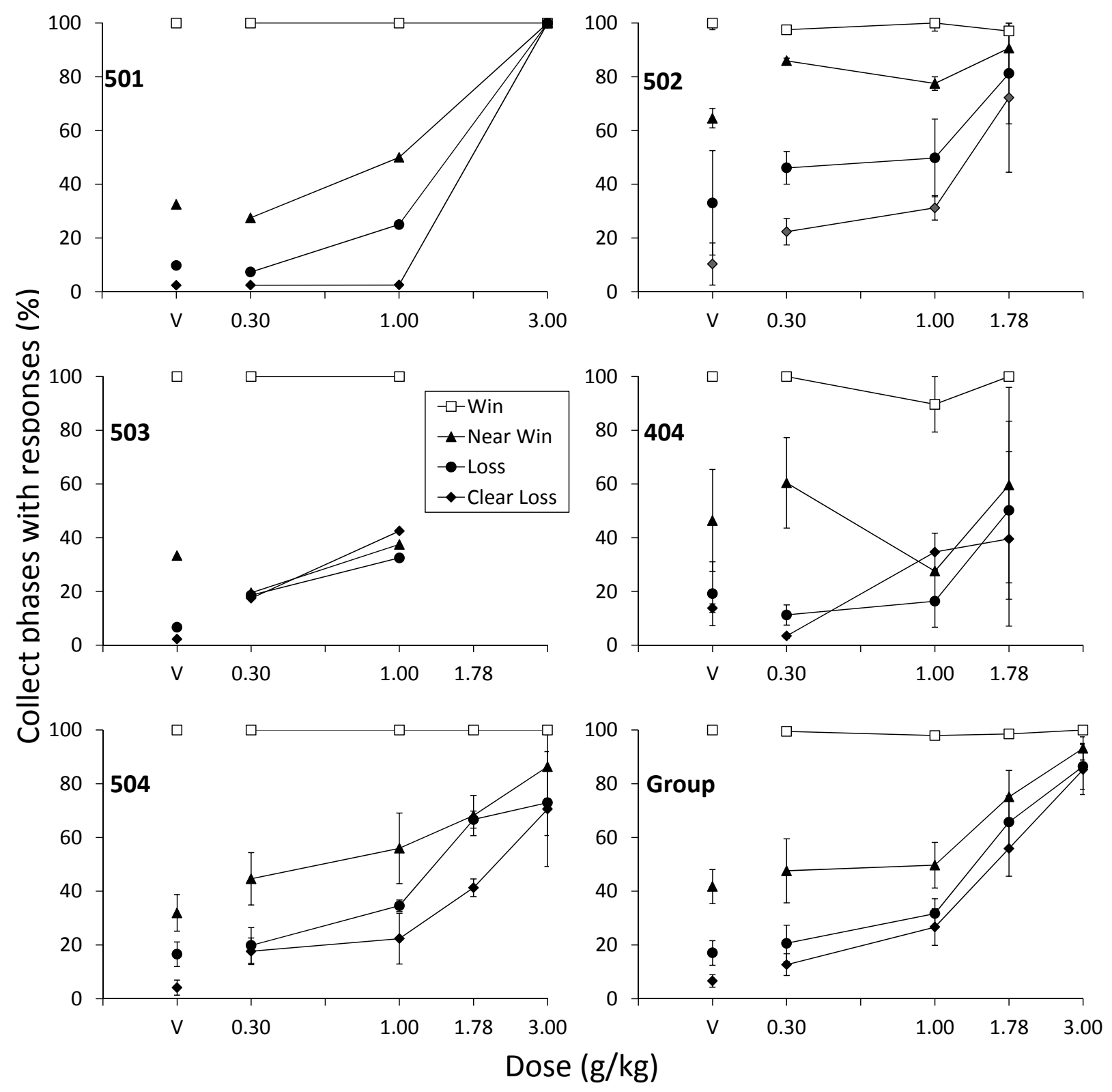

Figure 3. Percentage of trials in which pigeons pecked the collect key during the collect phase, plotted as a function of dose for each Pigeon. The bottom right graph shows proportions averaged across pigeons. Bars indicate standard error. 

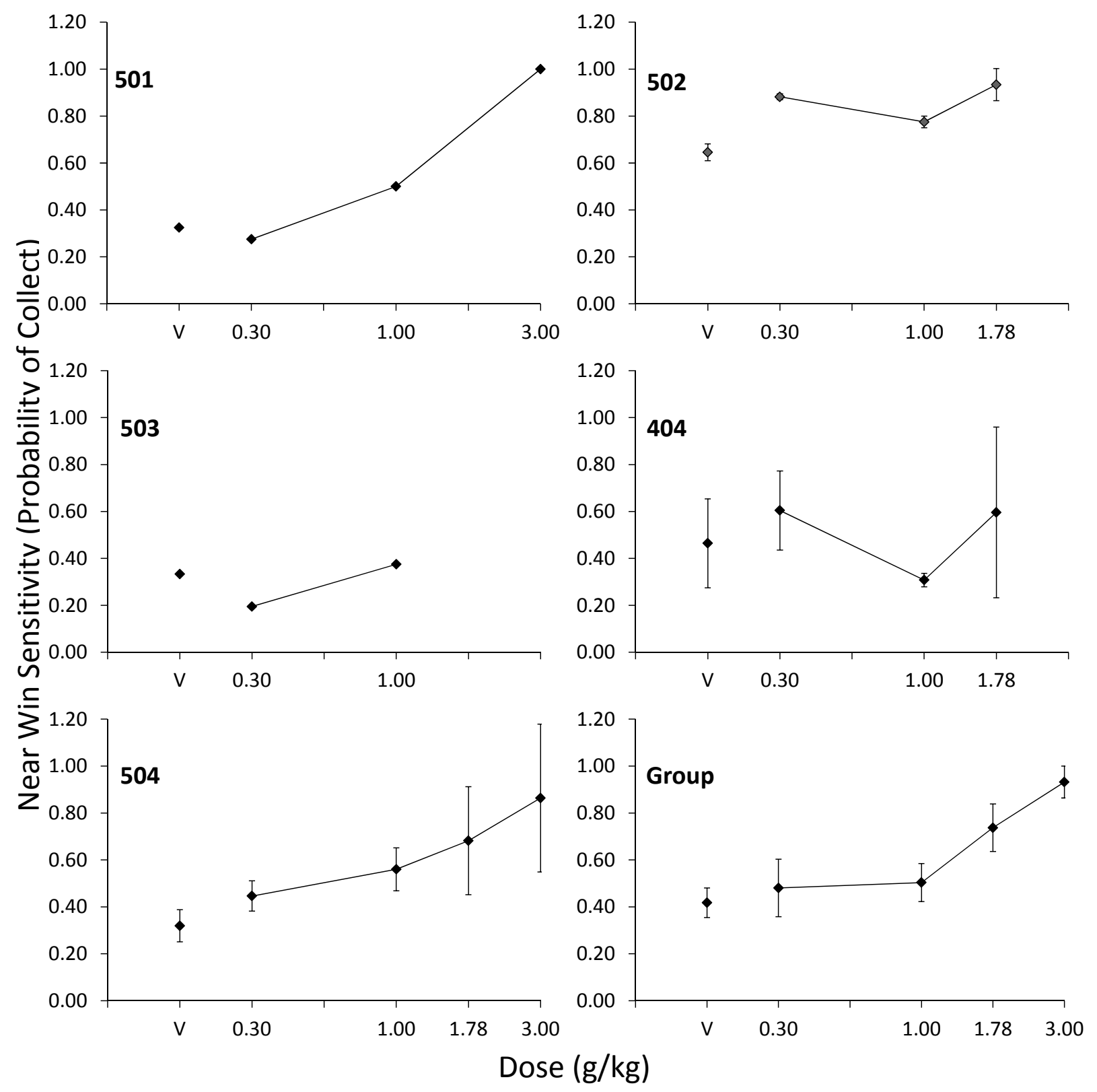

Figure 4. Ratio of near win response probability to win response probability plotted as a function of dose, calculated using probability data. Higher values indicate similarity between near win and win rates. A value near 1 means that response probability on near-win trials was similar to the probability of responding on win trials. The bottom right graph shows sensitivity to near wins averaged across pigeons. Bars indicate standard error. 


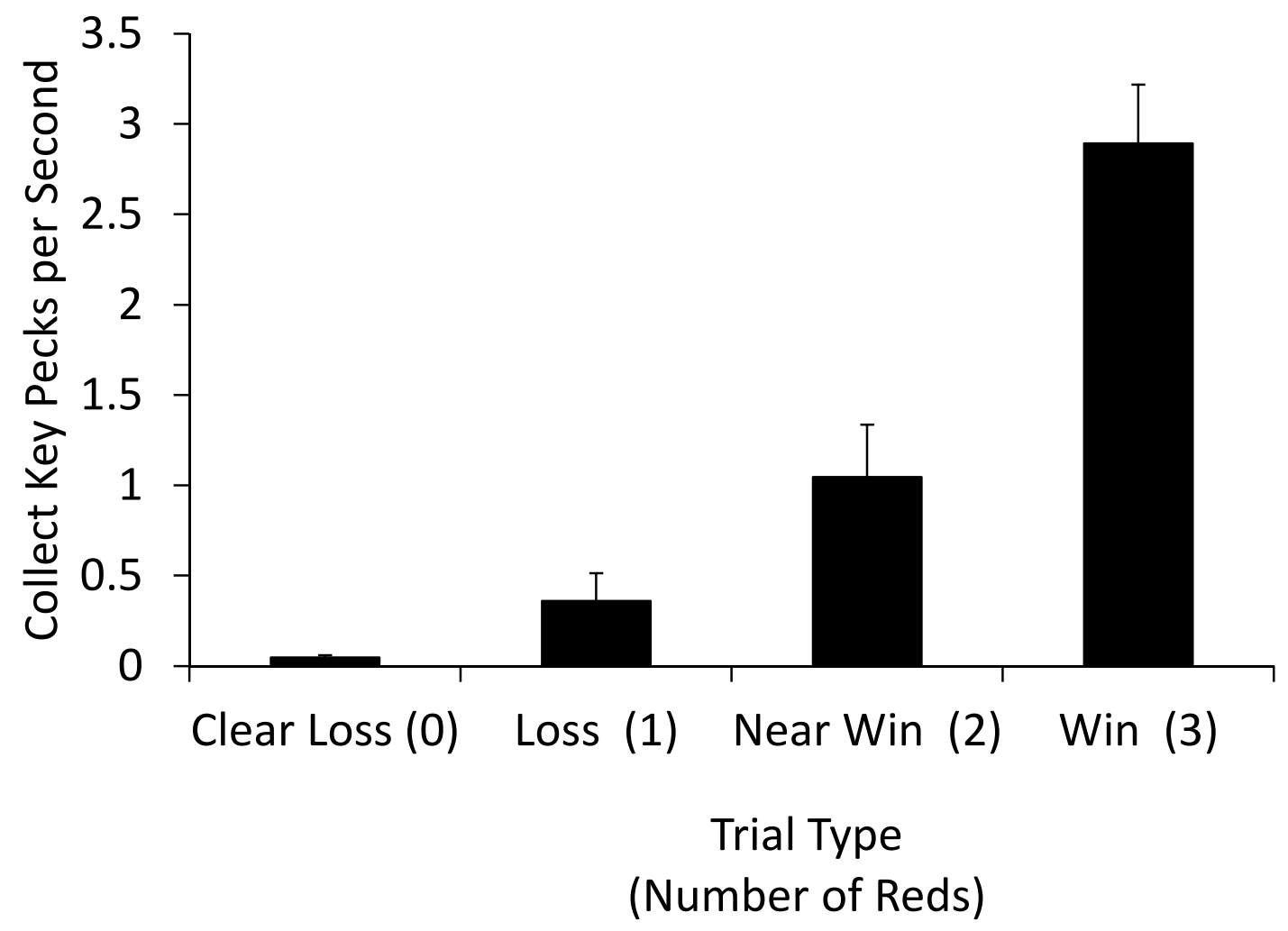

Figure 5. Mean response rate, calculated as pecks per s, on the collect key at vehicle dose plotted as a function of trial type, or the number of red lights in the response phase, averaged across pigeons at vehicle. Response rate on the collect key increased as a function of the number of red lights presented within the trial. Bars are standard error. 


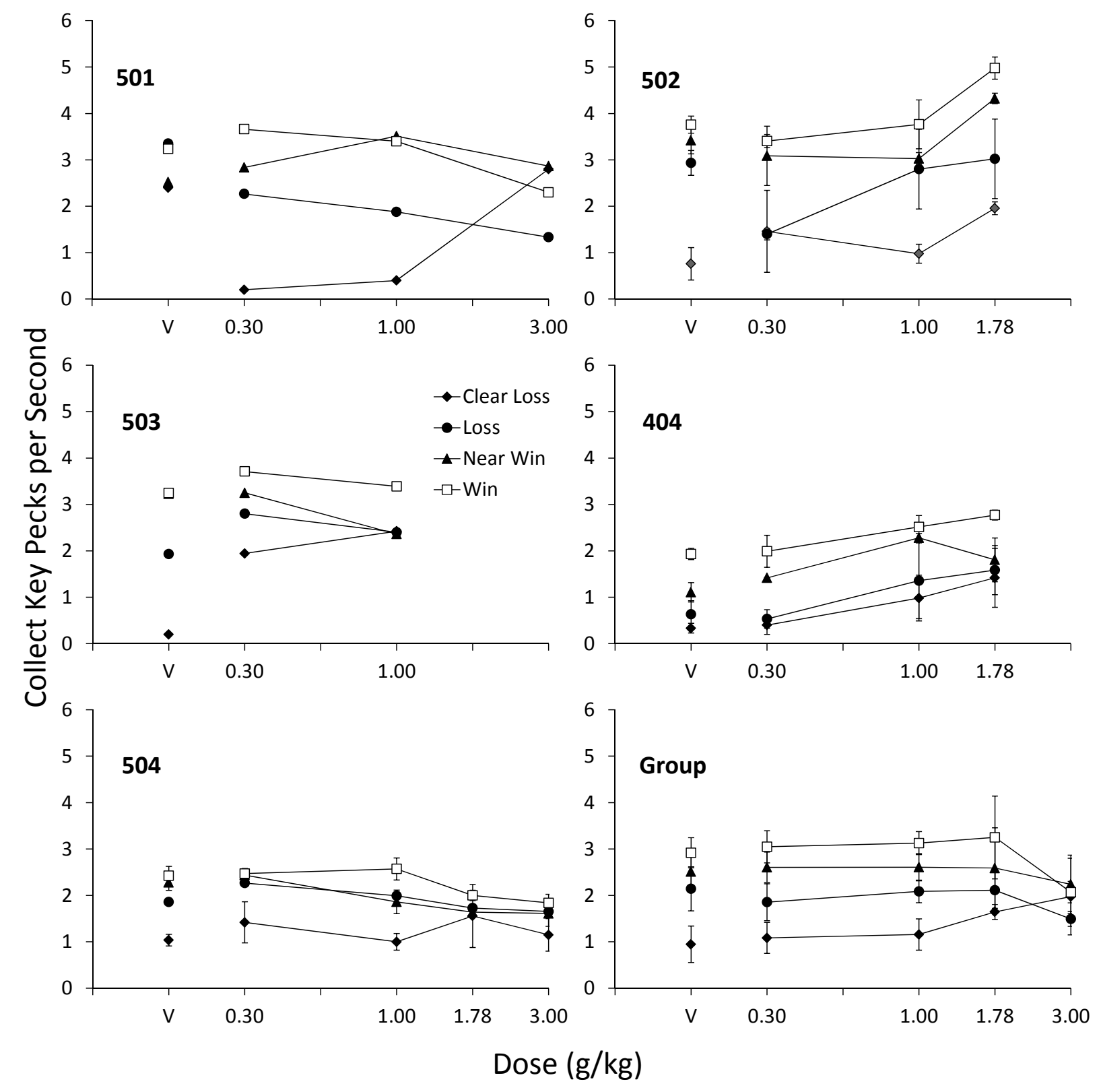

Figure 6. Response rates plotted as a function of ethanol dose $(\mathrm{g} / \mathrm{kg})$. Each data series in this figure represents one trial type. The bottom right graph shows response rates averaged across all pigeons. Bars indicate standard error. 


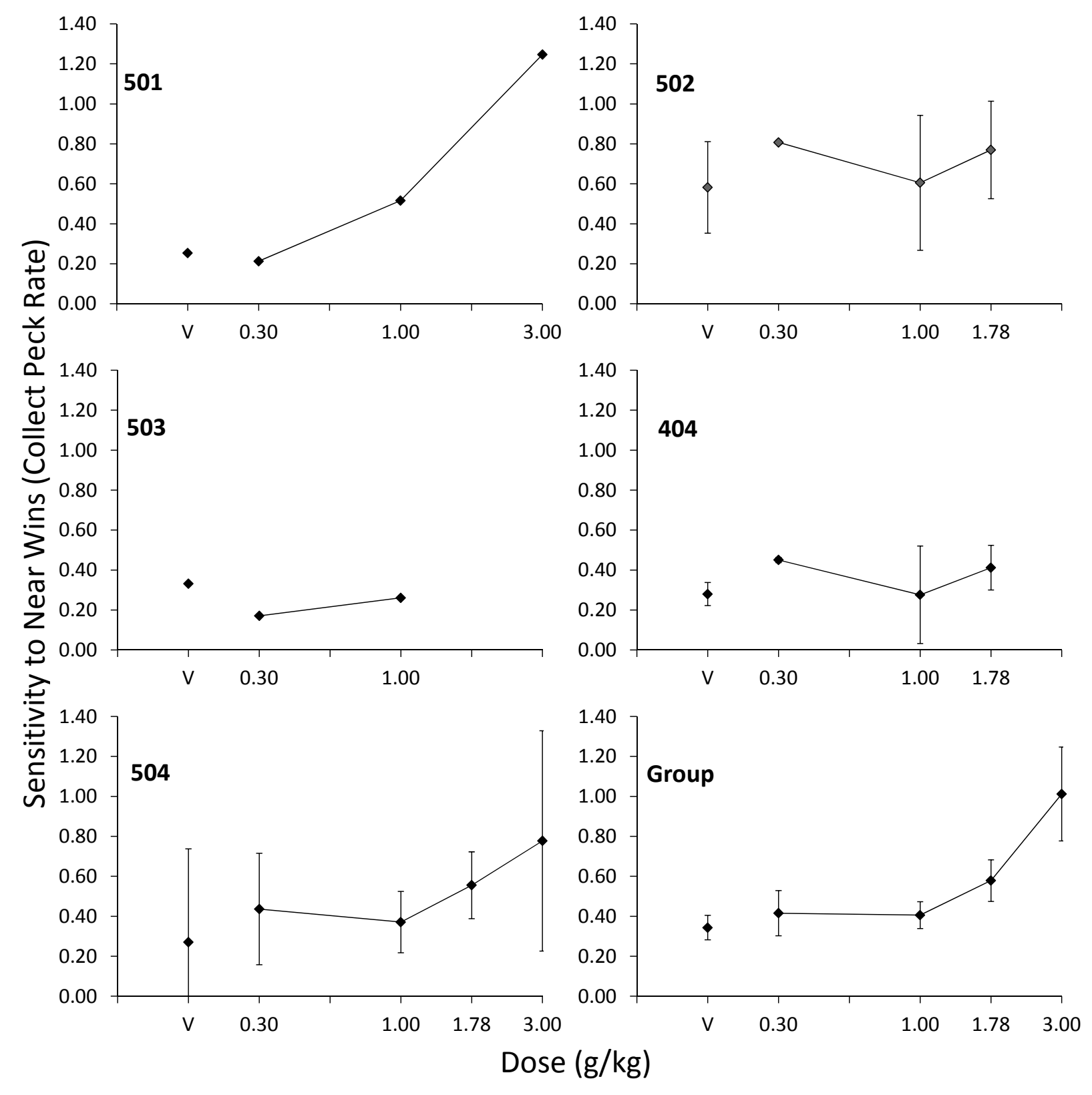

Figure 7. Ratio of near win response rate to win response rate plotted as a function of dose.

Higher values indicate similarity between near win and win rates. A value above 1 means that response rates on near-win trials was higher than responding on win trials. The bottom right graph shows sensitivity to near wins averaged across all pigeons. Bars indicate standard error. 


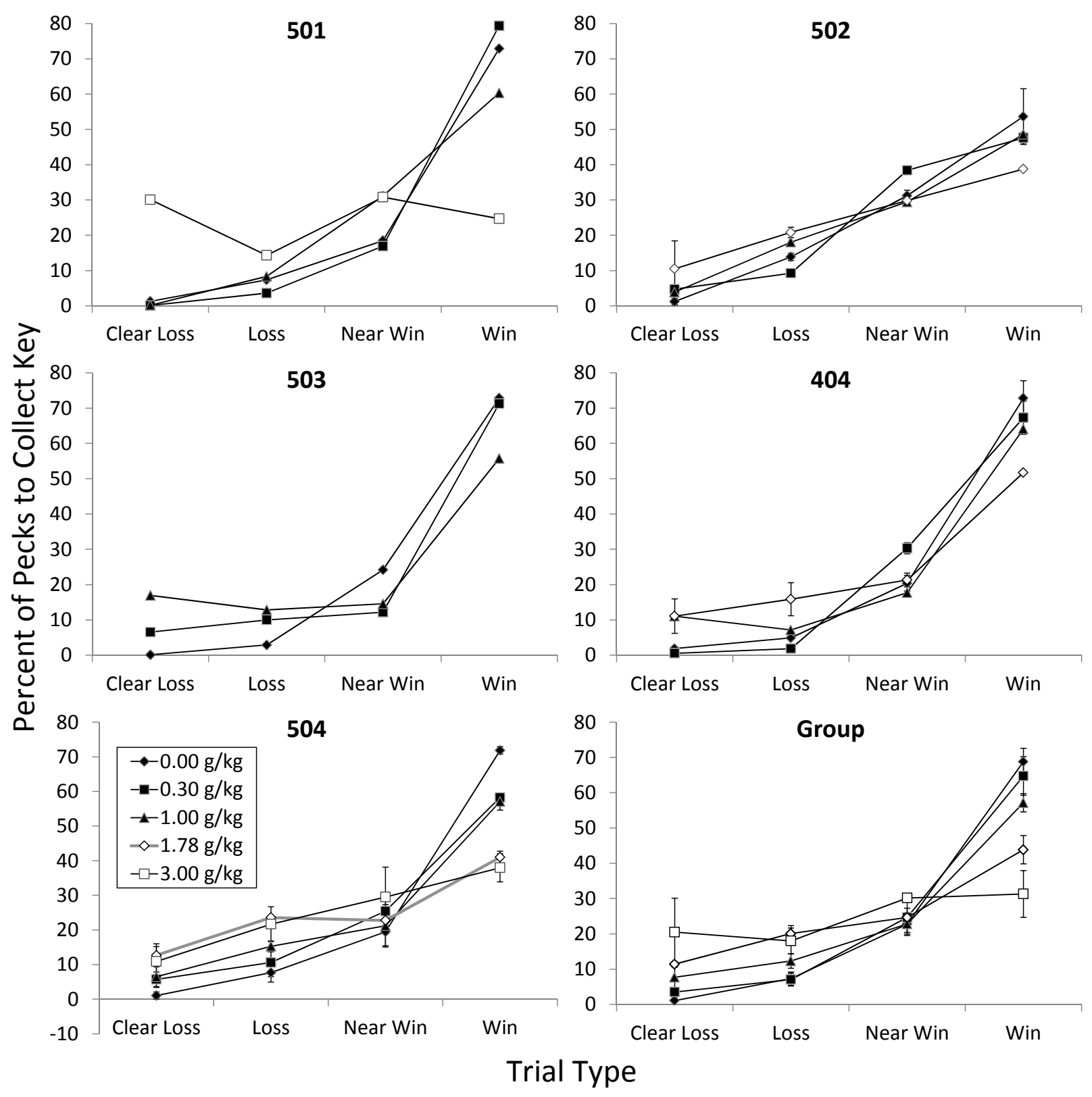

Figure 8. Percentage of the total pecks per opportunity allocated to the collect key for each trial type, plotted as a function of dose. Mean data are in the bottom right graph. The bars indicate standard error. 


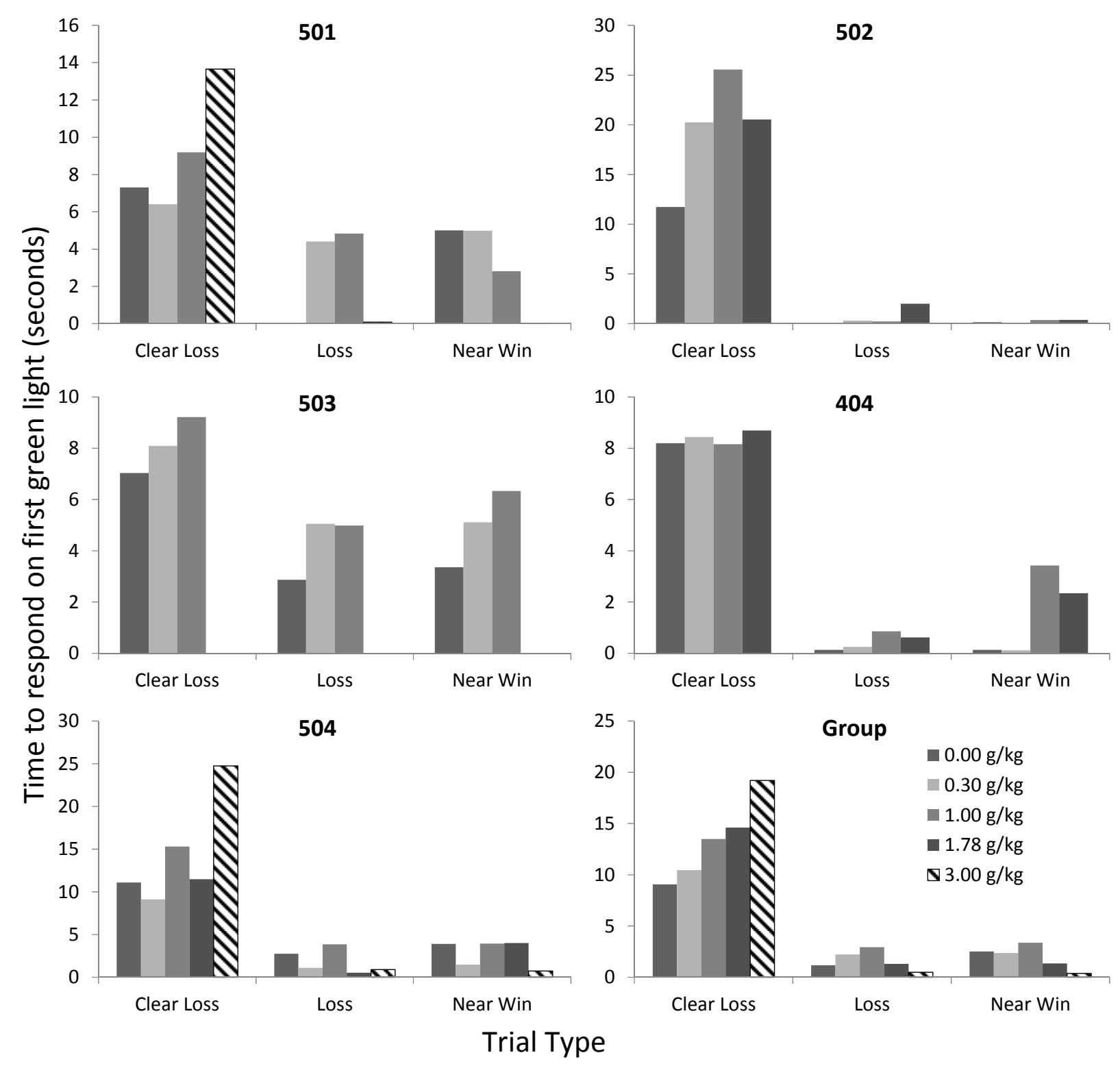

Figure 9. Mean time to respond on the first green light plotted as a function of trial outcome. The first green key presentation occurred first, second, and third in trials with zero, one, and two red keys, respectively. The bottom right graph shows latency to respond across all pigeons. 